GEOAMBIENTE ON-LINE

Revista Eletrônica do Curso de Geografia do Campus Jataí - UFG

www.jatai.ufg.br/geografia

| Jataí-GO | N.10 | jan-jun/2008 |
$\stackrel{\mathrm{E}}{\mathrm{C}}=\mathrm{E}$

İAMBIENTE

ISSN 1679-9860

\title{
ÍNDICES DE ARIDEZ APLICADOS AO SEMI-ÁRIDO PARAIBANO: DE MARTONNE, LANG, MEYER, CCD E XEROTÉRMICO
}

\section{$\left(\right.$ GAUSSEN $^{\bullet}$}

Kallianna Dantas Araujo ${ }^{1,2}$, Alberício Pereira de Andrade ${ }^{3}$, Roberto Wagner Cavalcanti Raposo $^{3}$, Paulo Roberto de Oliveira Rosa ${ }^{4}$, Eduardo Pazera $\mathrm{Jr}^{5}$

(1 - Adaptado de parte da Dissertação de Mestrado do primeiro autor, apresentada ao Programa de PósGraduação em Manejo de Solo e Água, Depto. de Solos e Eng. Rural (DSER), CCA, UFPB - Areia - PB, Brasil, financiado pela CAPES; 2 - Aluna de Doutorado do Programa de Pós Graduação em Recursos Naturais, CTRN/UFCG, E-mail: kdaraujo@yahoo.com.br; 3 - DSER, CCA, UFPB, Areia - PB, Brasil. E-mail: albericio@uol.com.br, robertowagner_raposo@yahoo.com.br; 4 - Depto de Geociências (DGEOC), CCEN, UFPB, João Pessoa - PB, Brasil. E-mail: paulorosa_ufpb@hotmail.com; 5 - Conselho de Proteção Ambiental do Estado da Paraíba (COPAM-PB). E-mail: pazera@terra.com.br).

\section{Resumo}

A alta variabilidade no decorrer do ano da precipitação pluviométrica e a elevada incidência da radiação solar e da temperatura são elementos que caracterizam o semi-árido paraibano e que favorecem as perdas de água do solo pelos processos de evaporação e evapotranspiração. A pesquisa teve como objetivo analisar o modelo que melhor representasse as variações meteorológicas mensais da área de São João do Cariri - PB, no intervalo de uma translação, compreendido entre o período de outubro de 2003 a setembro de 2004. Durante o período de realização da pesquisa foram analisadas variáveis meteorológicas (radiação solar, temperatura do ar, precipitação e umidade relativa do ar) e foram elaboradas estimativas de aridez através dos métodos climáticos de De Martonne, Lang, Meyer, CCD e xerotérmico (Gaussen). Os dados obtidos no presente trabalho permitem concluir que o índice de aridez calculado pelo modelo CCD foi o que representou melhor as variações mensais do tempo da região.

Palavras-chave: índices climáticos, semi-árido, desertificação.

\section{Abstract}

DRYNESS INDEXES APPLIED TO SEMIARID PARAIBA'S: DE MARTONNE, LANG, MEYER, CCD AND XEROTHERMIC (GAUSSEN)

\footnotetext{
- Recebido para publicação em 12 de Fevereiro de 2008; Aprovado para publicação em 06 de Junho de 2008
} 


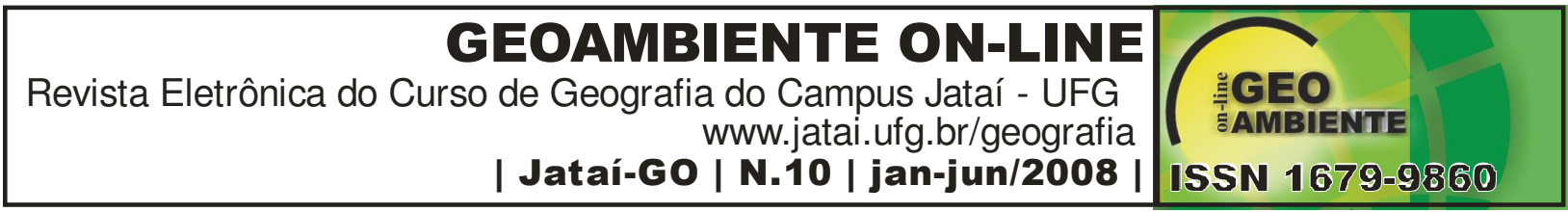

The high variability of the rainfall during the year and the high incidence of the solar radiation and the temperature are elements that characterize the semiarid of Paraiba state(BR) and that they favor the losses of water of the ground by the evaporation evapotranspiration processes. The purpose of the research was to analyze the model that better represented the monthly meteorological variations of the area of São João do Cariri - PB, in the interval of a translation, from o October of 2003 to September of 2004. During the period of accomplishment of the research there has been analyzed meteorological variables (solar radiation, air temperature, precipitation, relative humidity) and there was estimated the dryness through the climatic indexes of De Martonne, Lang, Meyer, CCD and Gaussen's xerothermic index. The data gotten in the present work allows concluding that the index of dryness calculated by the model CCD was the one that represented better the monthly variations of the weather of the region.

Key-words: climatic indexes, semiarid, desertification.

\section{1 - Introdução}

A escassez de água provocada pela má distribuição das precipitações pluviais e sua forma concentrada em certos períodos do ano, com elevada intensidade e alta magnitude (STRAHLER e STRAHLER, 1994), apresentando baixa umidade relativa do ar no período diurno e temperatura com grande variação diária e anual são elementos que caracterizam o semi-árido e o Cariri paraibano.

Em virtude da proximidade com o Equador, em alguns momentos da translação da Terra, a área de estudo recebe a incidência perpendicular dos raios solares iluminando de forma direta a superfície. Essas zonas com elevada radiação e insolação são denominadas de Cinturão Solar da Terra (BEZERRA, 1979).

O efeito dessa radiação sobre solos desnudos acelera as perdas de água pelo processo de evaporação e evapotranspiração, sobretudo nos meses inseridos no período seco da região (agosto a janeiro). A estimativa dessa perda de água pela evapotranspiração pode ser feita de forma direta utilizando-se instrumentos ou indireta empregando-se modelos baseados em dados climatológicos que condicionam a perda de água do solo para a atmosfera (MENEZES et al., 1980). Do mesmo modo, pode-se estimar o nível de aridez de um ambiente por meio de fórmulas baseados em dados climatológicos. Assim, quanto mais baixo for este índice mais árido é o clima (DAJOZ, 1985). 


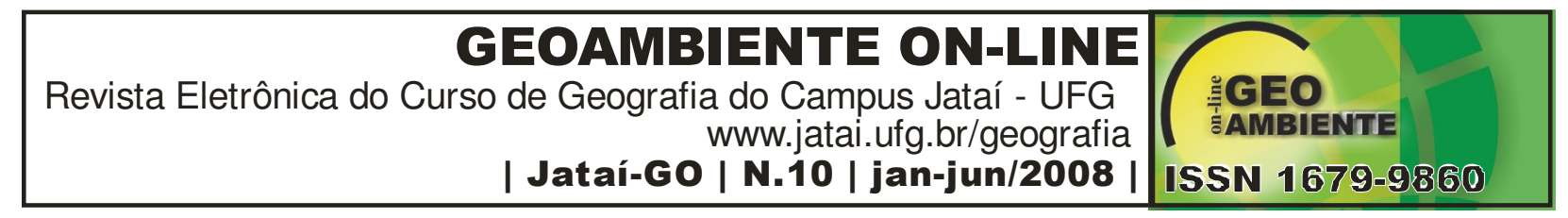

O dossel vegetal funciona como uma barreira tanto para a radiação que o atinge, como para aquela que é emitida pelo solo, o que resulta no estabelecimento de um microclima mais estável em seu interior (LIRA, 1999).

De forma complementar, Galvani et al. (2001) menciona que quando se forma um dossel homogêneo da cobertura vegetal, podem-se perceber pequenas variações dos valores de fluxo de calor no solo, devido ao sombreamento desse solo, diminuindo os níveis de radiação. Após a retirada da vegetação o fluxo de calor no solo volta a ser função do saldo de radiação disponível.

Nesse sentido, as atividades de desmatamento podem intensificar os processos naturais e, em alguns casos, desestabilizar a dinâmica natural do ambiente além do limiar da recuperação (DREW, 1986).

O objetivo do trabalho foi analisar o modelo que melhor representasse as variações meteorológicas mensais da região de São João do Cariri - PB.

\section{2 - Material e métodos}

O estudo foi realizado na Estação Experimental Bacia Escola (EEBE) - CCA/UFPB, localizada no município de São João do Cariri-PB, coordenadas $7^{\circ} 22^{\prime} 45,1^{\prime \prime} \mathrm{S}$ e $36^{\circ} 31^{\prime}$ 47,2" W, totalizando uma área de 500 ha, com altitude de $458 \mathrm{~m}$, inserida na Mesorregião da Borborema e Microrregião do Cariri Oriental, cujo macro relevo é a Superfície Aplainada do Planalto da Borborema (Figura 1) que apresenta um relevo suavemente ondulado sobre o Cristalino. 


\section{GEOAMBIENTE ON-LINE}

Revista Eletrônica do Curso de Geografia do Campus Jataí - UFG

| Jataí-GO | N.10 | jan-jun/2008

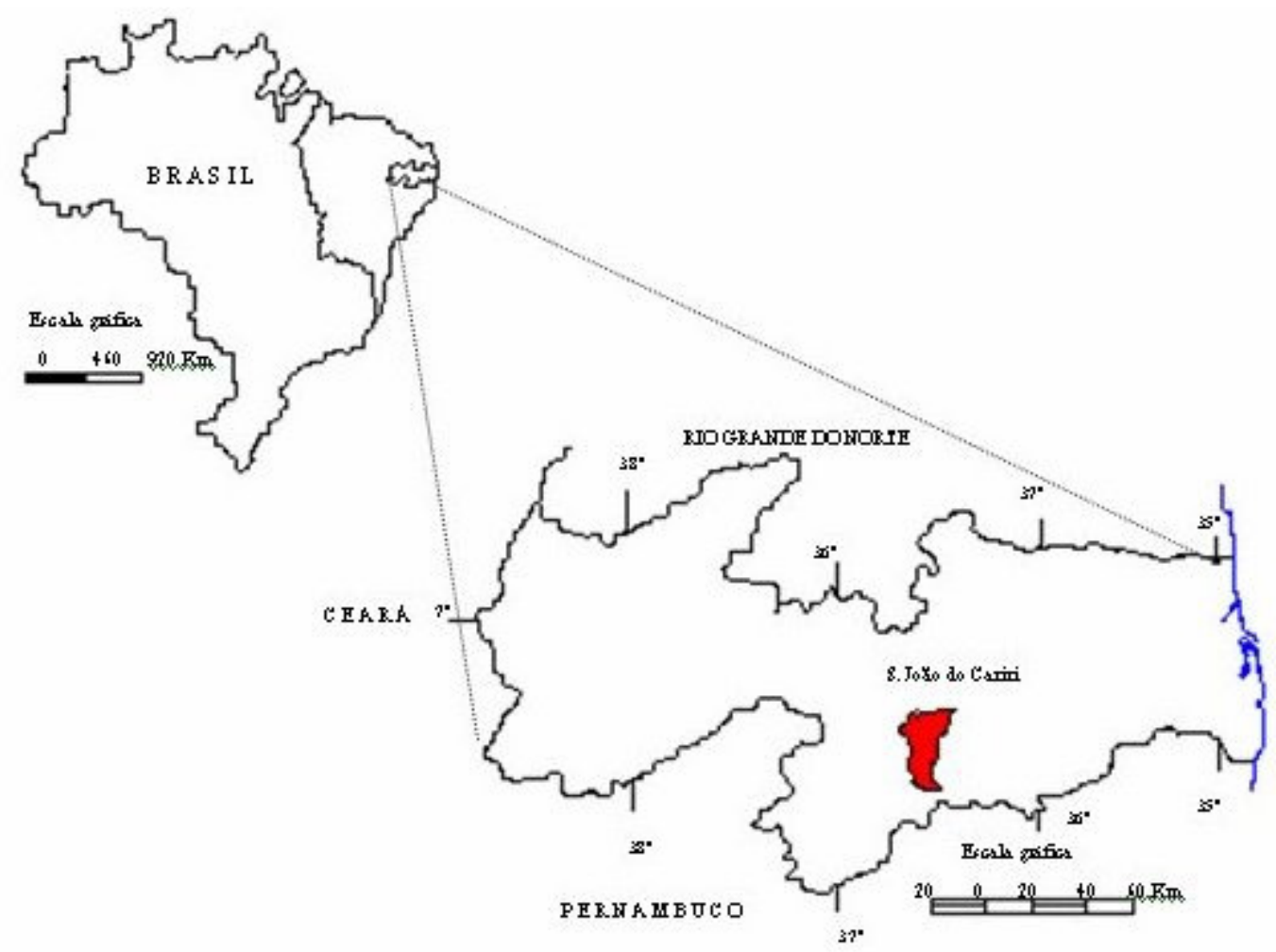

Figura 1. Localização de São João do Cariri - PB. Fonte: IBGE (2004).

O solo onde foi realizada a pesquisa é um Neossolo Lítico. O bioma encontrado é a Caatinga hiperxerófila decorrente do clima Bsh-quente com chuvas de verão, segundo Köppen e um Bioclima 2b com 9 a 11 meses secos denominado de subdesértico quente de tendência tropical, conforme Gaussen (ATLAS GEOGRÁFICO DA PARAÍBA, 1985). A média de precipitação é de $400 \mathrm{~mm} / \mathrm{ano}$, e a umidade relativa do ar é de $70 \%$.

Durante o período outubro de 2003 a setembro de 2004 foi efetuada a estimativa do índice de aridez através de parâmetros climáticos segundo as metodologias de De Martonne, Lang, Meyer, CCD e xerotérmico (Gaussen), assim como a Evapotranspiração Potencial (ETp).

O índice de aridez de De Martonne foi estimado a partir da aplicação do modelo:

$\mathrm{i}=\mathrm{P} /(\mathrm{T}+10)$

Onde:

$\mathrm{P}=$ representa a pluviosidade anual $(\mathrm{mm}) ;$

$\mathrm{T}=$ a temperatura média anual $\left({ }^{\circ} \mathrm{C}\right)$.

Para o cálculo do índice de aridez referente a um mês específico, foi aplicada a equação: 


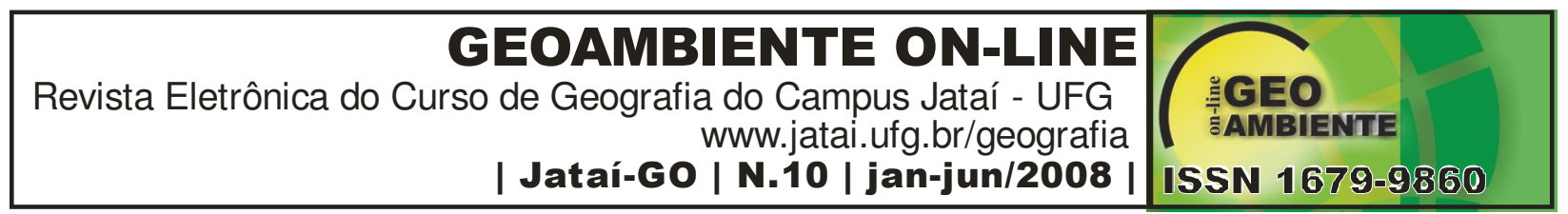

$\mathrm{i}=12 \mathrm{p} /(\mathrm{t}+10)$

Onde:

$\mathrm{p}=$ é a pluviosidade do mês em consideração (mm);

$\mathrm{t}=\mathrm{a}$ temperatura média do mesmo mês $\left({ }^{\circ} \mathrm{C}\right)$.

O índice de aridez varia de 0-5 (Desértico), 5-10 (Semidesértico), 10-20 (Estepes e países secos mediterrâneos), 20-30 (Região de cultivo de plantas de secano e cereais) (DAJOZ, 1978; PORTA et al., 1994).

O índice de Lang foi calculado, aplicando-se o modelo:

$\mathrm{I}=\mathrm{P} / \mathrm{T}$

Onde:

$\mathrm{P}=$ representa à precipitação anual média $(\mathrm{mm})$;

$\mathrm{T}=$ a temperatura média do ar anual $\left({ }^{\circ} \mathrm{C}\right)$.

O índice varia de 0-20 (Desértico), 20-40 (Zona Árida) e 40-60 (Zona úmida de estepe e savana) (PORTA et al., 1994).

O índice de Meyer foi calculado mediante a aplicação do modelo:

$\mathrm{I}=\mathrm{P} / \mathrm{DSA}$

O DSA é calculado a partir do modelo:

$\mathrm{DSA}=100-\mathrm{H} / 100 . \mathrm{T}$

Onde:

DAS = indica o déficit de saturação absoluta;

$\mathrm{H}=$ é a umidade relativa média (\%);

$\mathrm{T}=$ é a temperatura média do ar $\left({ }^{\circ} \mathrm{C}\right)$.

O índice de Meyer varia de 0-100 (Aridez, desertos, estepes) e de 100-275 (Semiárido) (PORTA et al., 1994).

O índice de aridez de acordo com a Convenção das Nações Unidas para o Combate à Desertificação e Mitigação dos Efeitos da Seca (CCD), considera Hiper-árido áreas com índice $(<0,05)$, Árido $(0,05<0,20)$, Semi-árido $(0,21<0,50)$, Subúmido-úmido seco $(0,51<$ 0,65), Sub-úmido e úmido $(>0,65)$. O índice foi calculado pela relação entre a precipitação pluviométrica e evapotranspiração potencial (ETp) (SRH/MMA, 2005).

A Evapotranspiração Potencial (ETp) foi estimada pelo modelo de Turc descrito por Dajoz (1978), a partir do modelo:

$\mathrm{ETp}=(\operatorname{Rg}+50) .0,4 .(\mathrm{t} / \mathrm{t}+5)$ 


\begin{tabular}{|r|l|}
\hline GEOAMBIENTE ON-LINE & \\
Revista Eletrônica do Curso de Geografia do Campus Jataí - UFG & www.jatai.ufg.br/geografia \\
| Jataí-Go | N.10 | jan-jun/2008 | & ISSN 1679-9860 \\
\hline
\end{tabular}

Onde:

$\mathrm{Rg}=$ representa à radiação solar global $\left(\mathrm{W} \mathrm{m}^{-2}\right)$;

$\mathrm{t}=\mathrm{a}$ temperatura média do $\operatorname{ar}\left({ }^{\circ} \mathrm{C}\right)$.

O índice xerotérmico (Gaussen) representa o período seco, pois considera que este se estabelece quando a pluviosidade mensal $(\mathrm{P}) \mathrm{em} \mathrm{mm}$ é inferior ao dobro da temperatura média mensal $(\mathrm{T})$, expressa em $\left({ }^{\circ} \mathrm{C}\right)(\mathrm{DAJOZ}, 1978)$. Para a FAO o índice xerotérmico $(\mathrm{d}=$ número de dias "secos" segundo o diagrama ombrotérmico. Classifica-se como: clima desértico $d>300$, clima subdesértico acentuado $250<d<300$, clima subdesértico atenuado $200<$ d $<250$ e clima xeromediterrâneo $150<$ d $<200$ (PORTA et al., 1994).

\section{3 - Resultados e discussão}

Do ponto de vista climático todos os índices (De Martonne, Lang, Meyer, CCD e Gaussen) apontam que a área no período estudado apresentou características de semi-aridez e/ou de aridez, embora a maior parte da pesquisa tenha sido desenvolvida em um ano atípico (outubro de 2003 a setembro de 2004) em termos de precipitação pluviométrica.

Segundo Strahler e Strahler (1994) o clima semi-árido apresenta uma precipitação pluviométrica variando entre 0 e $250 \mathrm{~mm}$ /anuais. O que se pressupõem riscos para o processo de desertificação, sobretudo no período mais crítico (meses que antecedem o solstício de verão).

De acordo com a afirmativa de Dajoz (1978) quanto mais baixo o índice mais árido é o clima. Assim, o menor valor e que indica a maior aridez foi verificado nos meses de outubro, novembro, dezembro (2003), bem como agosto e setembro (2004), período em que a aridez na área é mais intensificada, tendo sido constatado mediante a aplicação de todos os modelos.

De acordo com o índice de De Martonne observou-se que nesses meses o índice variou entre (0-5) caracterizando-se como desértico, apresentando a maior aridez em dezembro $(0,0)$ decorrente da ausência da precipitação. A menor aridez foi detectada no mês de janeiro $(92,0)$ em função da elevada precipitação, reduzindo-se nos meses subseqüentes, com uma queda em abril em virtude do declínio da precipitação, tendo sido denominado, segundo a classificação de De Martonne, como um mês semidesértico, já que a variação do índice manteve-se entre (5-10) (Tabela 1). Em termos anuais o valor médio do índice foi de 
21,13. Para Duarte (2003), há uma relação direta entre o índice de aridez e o processo de desertificação.

Tabela 1. Índice de aridez mensal pelo modelo de De Martonne para São João do Cariri PB, de outubro de 2003 a setembro de 2004

\begin{tabular}{ccccc}
\hline Meses & $\mathbf{P}(\mathbf{m m})$ & $\mathbf{T}\left({ }^{\mathbf{0}} \mathbf{C}\right)$ & $\mathbf{I}$ & Classificação \\
\hline Out & 0,5 & 26,6 & 0,163 & Desértico \\
Nov & 1,1 & 27,4 & 0,352 & Desértico \\
Dez & 0,0 & 28,0 & 0,000 & Desértico \\
Jan & 280,6 & 26,6 & 92,0 & Chuvoso \\
Fev & 165,1 & 24,8 & 56,93 & Chuvoso \\
Mar & 70,9 & 25,9 & 23,69 & Chuvoso \\
Abr & 15,7 & 26,0 & 5,23 & Semidesértico \\
Maio & 41,6 & 26,1 & 13,83 & Seco \\
Jun & 55,5 & 23,3 & 20,0 & Seco \\
Jul & 99,6 & 23,1 & 36,11 & Chuvoso \\
Ago & 9,5 & 23,7 & 3,38 & Desértico \\
Set & 5,6 & 24,8 & 1,93 & Desértico \\
\hline
\end{tabular}

$\mathrm{P}=$ Precipitação, $\mathrm{T}=$ Temperatura do ar, $\mathrm{I}=$ Índice de aridez

De acordo com o índice de Lang verificou-se que a média anual foi de 2,46 caracterizando-se como sendo uma zona árida. Avaliando a região em termos mensais, constatou-se que todos os meses apresentam características de desértico, sendo mais críticos os meses de outubro, novembro e dezembro (2003), além de agosto e setembro (2004) (Tabela 2).

Tabela 2. Índice de aridez mensal pelo modelo de Lang para São João do Cariri - PB, no período de outubro de 2003 a setembro de 2004

\begin{tabular}{ccccc}
\hline Meses & $\mathbf{P}(\mathbf{m m})$ & $\mathbf{T}\left(\mathbf{(}^{\mathbf{O}} \mathbf{)}\right.$ & $\mathbf{I}$ & Classificação \\
\hline Out & 0,5 & 26,6 & 0,018 & Desértico \\
Nov & 1,1 & 27,4 & 0,040 & Desértico \\
Dez & 0,0 & 28,0 & 0,000 & Desértico \\
Jan & 280,6 & 26,6 & 10,55 & Desértico \\
Fev & 165,1 & 24,8 & 6,66 & Desértico \\
Mar & 70,9 & 25,9 & 2,74 & Desértico \\
Abr & 15,7 & 26,0 & 0,604 & Desértico \\
Maio & 41,6 & 26,1 & 1,59 & Desértico \\
Jun & 55,5 & 23,3 & 2,38 & Desértico \\
Jul & 99,6 & 23,1 & 4,31 & Desértico \\
Ago & 9,5 & 23,7 & 0,401 & Desértico \\
Set & 5,6 & 24,8 & 0,226 & Desértico \\
\hline
\end{tabular}

$\mathrm{P}=$ Precipitação, $\mathrm{T}=$ Temperatura do ar, $\mathrm{I}=$ Índice de aridez 
Com base no Índice de Meyer observa-se que a região apresenta um índice anual médio de 7,07, caracterizado como sendo uma região árida, desértica ou de estepe como aponta o resultado. Mensalmente o índice permanece nessa escala de variação, sendo mais críticos os meses de outubro, novembro e dezembro (2003) e agosto e setembro (2004) (Tabela 3).

Tabela 3. Índice de aridez mensal pelo modelo de Meyer para São João do Cariri - PB, no período de outubro de 2003 a setembro de 2004

\begin{tabular}{ccccccc}
\hline Meses & $\mathbf{P}(\mathbf{m m})$ & $\mathbf{T}\left(\mathbf{~}^{\mathbf{O}} \mathbf{C}\right)$ & URa $(\%)$ & DSA $^{*}$ & I & Classificação \\
\hline Out & 0,5 & 26,6 & 48,0 & 13,83 & 0,036 & Árido \\
Nov & 1,1 & 27,4 & 48,4 & 14,14 & 0,078 & Árido \\
Dez & 0,0 & 28,0 & 48,9 & 14,31 & 0,000 & Árido \\
Jan & 280,6 & 26,6 & 66,1 & 9,02 & 31,19 & Árido \\
Fev & 165,1 & 24,8 & 61,7 & 9,50 & 17,38 & Árido \\
Mar & 70,9 & 25,9 & 52,3 & 12,35 & 5,74 & Árido \\
Abr & 15,7 & 26,0 & 49,7 & 13,08 & 1,20 & Árido \\
Maio & 41,6 & 26,1 & 62,6 & 9,76 & 4,26 & Árido \\
Jun & 55,5 & 23,3 & 72,3 & 6,45 & 8,59 & Árido \\
Jul & 99,6 & 23,1 & 71,1 & 6,68 & 14,92 & Árido \\
Ago & 9,5 & 23,7 & 59,6 & 9,57 & 0,992 & Árido \\
Set & 5,6 & 24,8 & 49,3 & 12,57 & 0,445 & Árido \\
\hline *DSA = Déficit de saturação absoluta, URa $=$ Umidade Relativa do ar, T $=$
\end{tabular}

Temperatura do ar, $\mathrm{P}=$ Precipitação, $\mathrm{I}=$ Índice de aridez

De acordo com o índice de aridez apresentado pela Convenção das Nações Unidas para o Combate à Desertificação e Mitigação dos Efeitos da Seca (CCD), a área de estudo apresentou um índice cuja variação foi de 0,0 (dezembro) a 1,96 (janeiro) com uma média anual de 0,44. Os meses de outubro, novembro, dezembro (2003) e setembro (2004) apresentaram características de clima hiper-árido, os meses denominados pelo CCD como subúmido-úmido foram janeiro, fevereiro e julho. Março, maio e junho foram classificados como semi-áridos e abril e agosto como árido (Tabela 4).

Tabela 4. Índice de aridez mensal pelo modelo CCD para São João do Cariri - PB, de outubro de 2003 a setembro de 2004

\begin{tabular}{ccccc}
\hline Meses & P $(\mathbf{m m})$ & ETp $(\mathbf{m m})$ & I & Classificação \\
\hline Out & 0,5 & 174,35 & 0,003 & Hiper-árido \\
Nov & 1,1 & 182,64 & 0,006 & Hiper-árido \\
Dez & 0,0 & 182,65 & 0,000 & Hiper-árido \\
Jan & 280,6 & 143,45 & 1,96 & Subúmido-úmido \\
Fev & 165,1 & 161,48 & 1,02 & Subúmido-úmido \\
Mar & 70,9 & 164,12 & 0,43 & Semi-árido \\
Abr & 15,7 & 148,61 & 0,106 & Árido \\
Maio & 41,6 & 127,10 & 0,327 & Semi-árido \\
Jun & 55,5 & 111,11 & 0,500 & Semi-árido
\end{tabular}




\section{GEOAMBIENTE ON-LINE}

Revista Eletrônica do Curso de Geografia do Campus Jataí - UFG www.jatai.ufg.br/geografia

| Jataí-GO | N.10 | jan-jun/2008 |
GEO

訁AMBIENTE

ISSN 1679-9860

\begin{tabular}{ccccc} 
Jul & 99,6 & 121,43 & 0,820 & Sub-úmido-úmido \\
Ago & 9,5 & 143,69 & 0,066 & Árido \\
Set & 5,6 & 156,02 & 0,036 & Hiper-árido \\
\hline
\end{tabular}

$\mathrm{P}=$ Precipitação, ETp = Evapotranspiração potencial, I = Índice de aridez

Com base no índice xerotérmico (Gaussen), ocorreram três períodos secos (outubrodezembro, abril, agosto-setembro) apresentando 100 eventos de precipitação, perfazendo um total de 326 dias secos. Sendo classificado como desértico de acordo com a classificação bioclimática da FAO (Porta et al., 1994). Os meses que antecederam o solstício de verão foram os que apresentaram maiores níveis críticos em termos de carência hídrica (Figura 2), estando próximos aos valores apresentados por Varejão-Silva (1984) cujo índice é de 200 a $300 \mathrm{~mm}$ para o município estudado, com estação seca muito longa, variando de 9 a 11 meses.

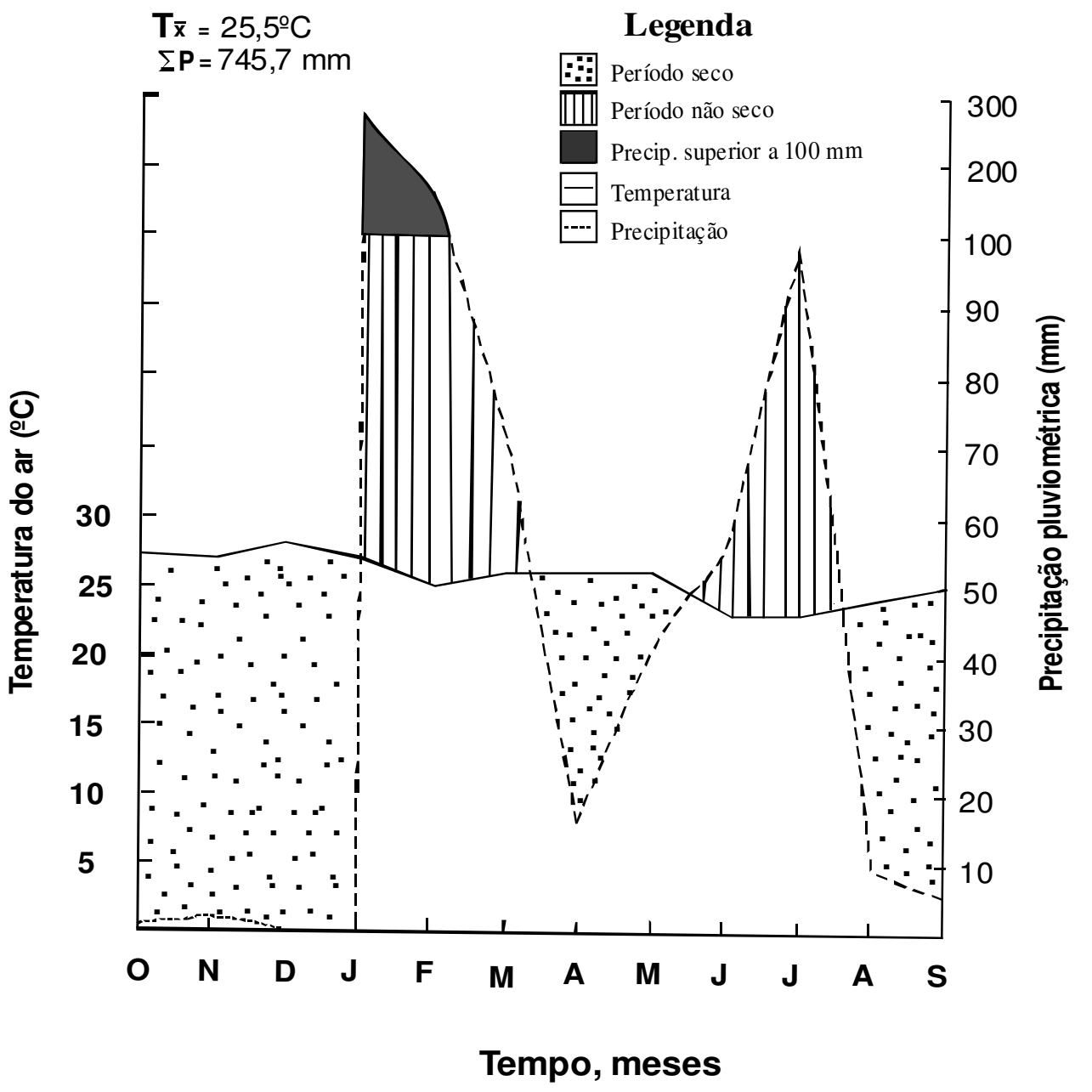

Figura 2. Diagrama ombrotérmico de São João do Cariri - PB referente ao período outubro de 2003 a setembro de 2004. 
Dos modelos utilizados para expressar o índice de aridez da região o de De Martonne e o CCD foram os que melhor se ajustaram às condições climáticas de São João do Cariri, mediante o tipo de classificação apresentada (Tabelas 1 e 4). Entretanto, a estimativa de aridez calculada pelo modelo CCD parece ser a mais adequada por considerar a evapotranspiração potencial da região no período estudado, sendo o modelo que melhor representou as variações mensais do tempo e conseqüentemente uma amostragem do clima da região. É importante ressaltar que esse índice utiliza a evapotranspiração potencial estimada pelo modelo de Turc que no seu cálculo usa somente a radiação solar e temperatura média do ar. Certamente, o maior entrave para a acurácia do modelo está na obtenção da Evapotranspiração. A evapotranspiração é mais precisa quando é obtida diretamente por meio de lisímetro, um equipamento ainda de rara utilização no país, que proporciona uma medida direta da ETp. Dos modelos usados na estimativa da evapotranspiração, o de PenmanMonteith é um dos mais sofisticados porque combina a equação do balanço de energia e os gradientes (variação) de temperatura, umidade e velocidade do vento. A maior dificuldade de aplicação de modelos mais sofisticados, no entanto, deve-se ao fato de poucas localidades disponibilizarem todos os dados necessários para sua utilização. Devido a este fato é que se usam modelos mais simples porque necessitam somente dados de temperatura e latitude, comumente encontrados em estações meteorológicas mais simples.

Pelo contrário, o índice de aridez anual calculado pelos modelos de Lang e Meyer não expressaram adequadamente as condições do clima do município. $\mathrm{O}$ índice de aridez anual pelo modelo de Lang classificou o clima do município de São João do Cariri como Desértico, enquanto que pelo modelo de Meyer como Árido.

De acordo com Varejão-Silva (1984) a Evapotranspiração potencial anual para São João do Cariri é de 1190 mm/ano. Por meio do modelo de Turc verificou-se que o valor encontrado para a área experimental foi de 1816,65 mm/ano, com uma média mensal de 151,39 mm. Houve uma variação da evapotranspiração ao longo do movimento de translação, nesse caso, os maiores valores foram constatados nos meses de outubro, novembro e dezembro, com uma redução em janeiro decorrente das elevadas precipitações. Os meses que apresentaram valores reduzidos foram: maio, junho e julho e a menor evapotranspiração foi verificada em junho $111,11 \mathrm{~mm}$ (Tabela 5). 


\section{GEOAMBIENTE ON-LINE}

Revista Eletrônica do Curso de Geografia do Campus Jataí - UFG www.jatai.ufg.br/geografia

| Jataí-GO | N.10 | jan-jun/2008

Tabela 5. Estimativa da Evapotranspiração potencial (ETp) pelo modelo de Turc, Radiação solar e temperatura referente ao período de outubro de 2003 a setembro de 2004

\begin{tabular}{|c|c|c|c|}
\hline Meses & Radiação solar $\left(\mathbf{W} \mathbf{m}^{-2}\right)$ & Temperatura $\left({ }^{\circ} \mathbf{C}\right)$ & $\operatorname{ETp}(\mathbf{m m})$ \\
\hline Out & 467,7 & 26,6 & 174,35 \\
\hline Nov & 489,9 & 27,4 & 182,64 \\
\hline Dez & 488,3 & 28,0 & 182,65 \\
\hline Jan & 376,0 & 26,6 & 143,45 \\
\hline Fev & 435,1 & 24,8 & 161,48 \\
\hline Mar & 439,4 & 25,9 & 164,12 \\
\hline Abr & 392,9 & 26,0 & 148,61 \\
\hline Maio & 328,6 & 26,1 & 127,10 \\
\hline Jun & 287,3 & 23,3 & 111,11 \\
\hline Jul & 319,4 & 23,1 & 121,43 \\
\hline Ago & 385,0 & 23,7 & 143,69 \\
\hline Set & 418,7 & 24,8 & 156,02 \\
\hline
\end{tabular}

ETp $=$ Evapotranspiração potencial

A radiação solar e a temperatura são dois dos principais fatores que influenciam na perda de água no solo (Klar, 1984). Assim, durante o período do experimento observou-se uma relação direta entre a radiação solar e a ETp, em que a curva da ETp tende a acompanhar a curva da radiação solar, apresentando a interdependência entre esses fatores (Figura 4).

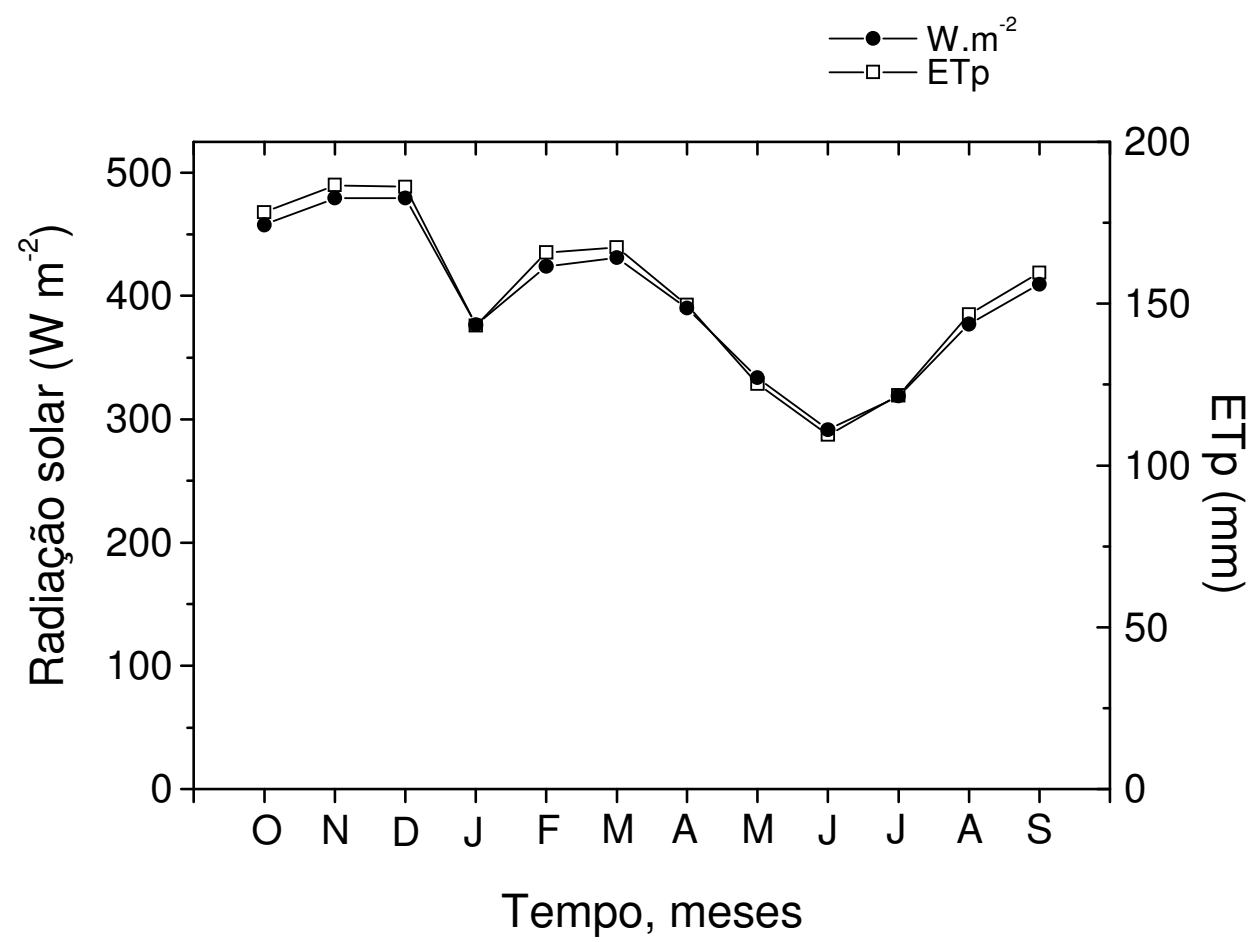




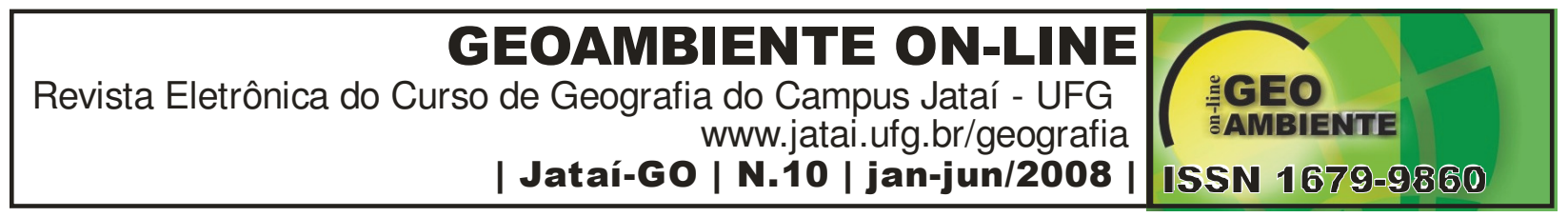

Figura 4. Variação da ETp em função da radiação solar referente ao período de outubro de 2003 a setembro de 2004.

\section{4 - Conclusões}

- $\quad$ O índice de aridez calculado pelo modelo CCD foi o que representou melhor as variações mensais do tempo e consequentemente o clima da região;

- A maior incidência da radiação solar foi verificada nos meses de agosto, setembro, outubro, novembro e dezembro, coincidindo com os meses de maiores taxas de evapotranspiração.

\section{5 - Referências bibliográficas}

BEZERRA, A. M. Aplicações Térmicas da Energia Solar. João Pessoa: Ed. UFPB, 1979. $123 p$.

DAJOZ, Roger. Ecologia geral. Petrópolis: Vozes, 1978.

DREW, D. Processos interativos homem - meio ambiente. Trad. de João Alves dos Santos: revisão de Suely Bastos, São Paulo: DIFEL, 1986. 206p.

DUARTE, J. J. Desertificação do semi-árido paraibano. Conceitos. João Pessoa, v.9, n.9, p.53-60, jan/jun. 2003.

GALVANI, E.; ESCOBEDO, J. F.; PEREIRA, A. B. Balanço de radiação e fluxo de calor no solo em ambiente natural e protegido cultivado com pepineiro. Bragantia, Campinas, v. 60, n.2, p.139-147, 2001.

GOVERNO DO ESTADO DA PARAÍBA. Secretaria da Educação. Universidade Federal da Paraíba. Atlas Geográfico da Paraíba. João Pessoa, Grafset, 1985.

INSTITUTO BRASILEIRO DE GEOGRAFIA E ESTATÍSTICA. Disponível em: <http://www.ibge.gov.br/cidadesat/default.php>. Acesso em: Setembro 2004.

LIRA, A. C. S. de. Comparação entre povoamento de eucalipto sob diferentes práticas de manejo e vegetação natural de cerradão, através da respiração, infiltração de água e mesofauna do solo. 1999. 70f. Dissertação (Mestrado em Ciências) - Escola Superior de Agricultura Luiz de Queiroz, Universidade de São Paulo, Piracicaba.

KLAR, A. E. A água no sistema solo-planta-atmosfera. São Paulo: Nobel, 1984. 408p. 


\section{GEOAMBIENTE ON-LINE}

Revista Eletrônica do Curso de Geografia do Campus Jataí - UFG www.jatai.ufg.br/geografia

| Jataí-GO | N.10 | jan-jun/2008

MENEZES, L. A. de; SOUZA, J. L. de; FERNANDEZ, R.; MEDEIROS, J. X. de. Cálculo da evapotranspiração potencial de Nazaré da Mata - PE. 1980. Areia. Anais... Areia: PPGMSA/UFPB/CCA/DSER, 1980. Resumo.

PORTA, J.; ACEVEDO, M. L.; ROQUERO, C. Edafologia: para la agricultura y el medio ambiente. Madrid: Ediciones Mundi-Prensa, 1994.

SRH/MMA. SECRETARIA DE RECURSO HÍDRICOS. MINISTÉRIO DO MEIO AMBIENTE. Combate à desertificação. Uma luta nacional. Disponível em: $<$ http://desertificacao.enrh-srh.gov.br>. Acesso em: Janeiro 2005.

STRAHLER, A., STRAHLER, A. H. Geografia física. Trad. de Marta Barrutia e Pere sunyer. $3^{\mathrm{a}}$ ed. Barcelona: OMEGA, 1994. 550p.

VAREJÃO-SILVA, M. A. Atlas climatológico do Estado da Paraíba. Campina Grande: Universidade Federal da Paraíba, Núcleo de Meteorologia Aplicada. 1984. 